\title{
Remote sensing of early-stage green tide in the Yellow Sea for floating- macroalgae collecting campaign
}

\author{
Qianguo Xing ${ }^{\mathrm{a}, \mathrm{b}, *}$, Lingling $\mathrm{Wu}^{\mathrm{a}, \mathrm{b}}$, Liqiao Tian ${ }^{\mathrm{c}}$, Tingwei Cui ${ }^{\mathrm{d}}$, Lin $\mathrm{Li}^{\mathrm{a}}$, Fanzhou Kong ${ }^{\mathrm{e}}$, \\ Xuelu Gao ${ }^{\mathrm{a}, \mathrm{b}}$, Mengquan $\mathrm{Wu}^{\mathrm{f}}$ \\ ${ }^{\text {a }}$ Key Laboratory of Coastal Environmental Processes and Ecological Remediation, Yantai Institute of Coastal Zone Research, Chinese Academy of Sciences, China \\ ${ }^{\mathrm{b}}$ University of Chinese Academy of Sciences, Beijing, China \\ ${ }^{\mathrm{c}}$ State Key Laboratory of Information Engineering in Surveying, Mapping and Remote Sensing, Wuhan University, 129 Luoyu Road, Wuhan 430079, China \\ ${ }^{\mathrm{d}}$ First Institute of Oceanography, State Oceanic Administration, 6 Xianxialing Road, Qingdao 266061, China \\ e Institute of Oceanography, Chinese Academy of Sciences, 6 Nanhai Road, Qingdao, China \\ ${ }^{\mathrm{f}}$ Ludong University, Yantai, China
}

\section{A R T I C L E I N F O}

\section{Keywords:}

Green tide

Early-stage bloom

Growth rate

Biomass

Floating macroalgae harvesting

High-resolution satellite image

The Jiangsu Shoal

The Yellow Sea

\begin{abstract}
A B S T R A C T
The world's largest green tide originated from the Jiangsu Shoal of the Yellow Sea was due to fast reproduction of floating green macroalgae (Ulva prolifera). It brought significant impacts on marine environment and ecosystem in the Yellow Sea. In this study, we examined the expansion of green tide from the Jiangsu Shoal during the period from 29 April to 25 June 2016. Using high-resolution satellite images, we revealed a declined growth rate during the northward drifting of early-stage green tide for the first time, i.e., the green tide had higher growth rate (up to 25\% per day) in the turbid waters of the Jiangsu Shoal in May and a lower growth rate (low to $3 \%$ per day) in the relatively clear waters in the middle of the western Yellow Sea in June, which suggests that water clarity might not be the key factor controlling the growth rate of the floating macroalgae in the surface waters under natural conditions. The high growth rate led to shortened time windows for controlling the green tide by employing macroalgae collecting campaigns at the initial sites of the green tide, which was no more than 14 days in the 2016 case.
\end{abstract}

\section{Introduction}

Macroalgal blooms (MABs) caused by fast growth and accumulation of macroalgae, e.g., green macroalgae of Ulva prolifera and brown macroalgae of Sargassum, have been increasing in recent years in the global oceans (Liu et al., 2009; Gower et al., 2013; Smetacek and Zingone, 2013; Xing and Hu, 2016; Xing et al., 2017). These large-scale blooms can bring significant adverse ecological and economic impacts on marine and coastal areas (Wang et al., 2009; Xing et al., 2015a; Liu et al., 2016; Li et al., 2018).

The world's largest green tide caused by the Ulva prolifera blooms in the Yellow Sea was reported to occur in every late spring and summer since 2007 (Hu and He, 2008; Xing et al., 2009, 2011; Hu et al., 2010; Keesing et al., 2011; D. Liu et al., 2013; Hu et al., 2017). This led to the speculation that the green tide in the Yellow Sea was caused by recycling aquaculture facilities for growing seaweed - Poryphyra yezoensis - at the Jiangsu Shoal of the southern Yellow Sea at the end of April (Liu et al., 2009; D. Liu et al., 2013a; F. Liu et al., 2013; Wang et al., 2015); that is, green macroalgae originally grow on the seaweed aquaculture facilities of poles, ropes and nets. After the last round of seaweed harvesting in every April, green macroalgae thallus are removed and discarded into sea water when the facilities are recycled. The unattached macroalgae grow and expand in sea water, and eventually form largescale green tide in the southern Yellow Sea during April-August, with a peak in June (Liu et al., 2009, 2013a; D. Liu et al., 2013; Keesing et al., 2011; Xing et al., 2015b; Liu et al., 2016; Qi et al., 2016; Hu et al., 2017).

Considering the fact that the green macroalgae may be used as fertilizer, food, biofuel materials, so on, the Ulva green tide may be controlled at the initial sites by collecting the macroalgae before the green tide is out of control due to the expansion of its biomass (Lotze et al., 1999; Liu et al., 2017). Compared to the fully-developed largescale green tide, the initial early-stage small-scale MABs are more important for exploring the origin and causes of full-bloom green tide. So,

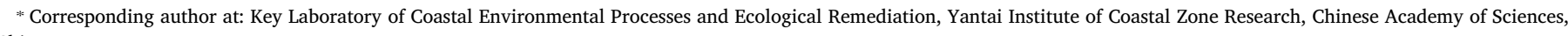
China.

E-mail addresses: qgxing@yic.ac.cn (Q. Xing), llwu@yic.ac.cn (L. Wu), tianliqiao@whu.edu.cn (L. Tian), cuitingwei@fio.org.cn (T. Cui), fzkong@qdio.ac.cn (F. Kong), mqwu@ldu.edu.cn (M. Wu).
} 
monitoring the development of early-stage green tide is an essential step to carry out effective countermeasures.

Through satellite remote sensing, researchers reported the world's largest MABs of Ulva prolifera in Summer 2008, and explored their possible causes (Hu and He, 2008; Liu et al., 2009; Shi and Wang, 2009; Xing et al., 2009). The seasonal dynamics of MABs in the East China Sea (ECS) and the Yellow Sea (YS) have been documented (Keesing et al., 2011; Xing et al., 2011, 2015b; Qi et al., 2016; Hu et al., 2017); and the MABs in the YS were tracked back to the year of 1999 (Xing and Hu, 2016). However, most of the findings were based on low- and moderate-resolution images $(250-500 \mathrm{~m})$, which failed to reveal small macroalgae patches or wrongly classified them (Hu et al., 2010; Xing et al., 2011; Ding et al., 2015; Q. Xu et al., 2016; F. Xu et al., 2016; Zheng et al., 2016); consequently, the MABs may be overlooked or overestimated (Ding et al., 2015; Xiao et al., 2017), especially for the early-stage small-scale MABs.

The Normalized Difference of Vegetation Index (NDVI) may be the most used index for detecting MABs in offshore waters in the southern Yellow Sea (Hu and He, 2008; Xing et al., 2010; Cui et al., 2012). However, this index is very sensitive to environmental conditions, and is affected by aerosols, sea surface glints and water constituents $(\mathrm{Hu}$, 2009; Garcia et al., 2013). To reduce spatial variation in large-size image, such an image is divided into small windows, and targets can then be identified window by window (Xing et al., 2011; Garcia et al., 2013; Meng and Xing, 2013). Specific indices for different satellite cameras were also designed to mitigate these impacts (Hu, 2009; Son et al., 2012, 2015; Wang and Hu, 2016). The band-difference indices, such as the Floating Algae Index (FAI), the Virtual Baseline Floating macroAlgae Height (VB-FAH), the Difference of Vegetation Index (DVI) between near-infrared and red bands for MABs detection, were tested and shown to be less sensitive to aerosol variation and sea surface glints than the NDVI, and are suitable for high-resolution images with limited blue, green, red, and near-infrared bands $\mathrm{Hu}, 2009$; Xing and $\mathrm{Hu}$, 2016).

Since it is now known that the green tide (macroalgae) originated from the Poryphyra yezoensis farming rafts, can the green tide be controlled by adopting countermeasures at the initial sites of the Jiangsu Shoal? Many suggestions have been put forward to control the early blooms of green tide, such as disposing macroalgae when recycling the Poryphyra yezoensis farming rafts (D. Liu et al., 2013), recycling farming facilities as early as possible (Liu et al., 2017), cutting down nutrient input (F. Liu et al., 2013), removing the farming industry of Poryphyra yezoensis, adjusting the farming location, replacing the materials used for making rafts, raising macroalgae-eating animals, using chemicals to kill or control the macroalgae on the rafts, collecting the early-stage macroalgae, and so on (personal communications with Dr. Song Qin, Dr. Chuanming Hu, Dr. Song Sun, and so on). However, this is a difficult task when the environmental, ecological, economic and social effects, and the feasibilities are concerned. Relatively speaking, the early-stage collecting campaign has several major merits. First, it is environmentfriendly. Second, the macroalgae may be used as resource, and thus there is a potential of collecting them in a commercial way. Third, the effectiveness can be seen immediately. Then, the question becomes, can the early-stage collecting work be done in a cost-effective and feasible way? In this work, high-resolution satellite images are used in a biomass-estimation model to explore the features in the expansion of earlystage green tide in the Yellow Sea, and to assess the feasibility of using the macroalgae collecting approach to control their spread.

\section{Data and methods}

\subsection{The study area}

Fig. 1 shows the study area of the Jiangsu Shoal and its vicinity. The true color image, a composite of satellite images bands 3 (red), 2 (green) and 1 (blue) acquired on 29 April 2016, shows the Jiangsu
Shoal where the water was shallow and full of suspended sediments. Fig. 2 shows the tidal flat was dominated by the seaweed aquaculture of Poryphyra yezoensis.

\subsection{Satellite images and processing}

In this study, satellite images during the period of April-June 2016 were collected and used for MABs extraction, including the GaoFen-1 (GF-1), China-Brazil Earth Resources Satellite-4 (CBERS-4) and the Moderate Resolution Imaging Spectrometer (MODIS). Specifically, the red band (Red) and near-infrared band (NIR) data acquired by these sensors were processed to give top-of-atmosphere reflectance $(R$, unitless). Then, the DVI, the reflectance difference between the NIR band and the Red band $\left(\mathrm{R}_{\mathrm{NIR}}-\mathrm{R}_{\mathrm{Red}}\right)$, which has a linear correlation to the coverage of floating plants at the sea surface (Xing and Hu, 2016; Xing et al., 2017), was calculated for each image. The spatial resolutions of GF-1, CBERS-4 and MODIS used in this work are 16, 30 and $250 \mathrm{~m}$, respectively. In practice, the high-resolution GF-1 and CBERS-4 images were used to monitor the early-stage MABs, which might be overlooked in the lower- and moderate-resolution images (e.g., the MODIS).

Macroalgae pixels have higher DVI values than the background seawater. In this work, a dynamic threshold of DVI was used to extract macroalgae pixels. The DVI images were segmented into small windows, and a threshold was set to classify the macroalgae pixels window by window, i.e., pixels with their DVI values larger than the threshold (from -0.02 to 0.01 ) depending on the water surface optical conditions, were regarded as macroalgae pixels. Meanwhile, the R(band 4)G(band 3)-B(band 2) false-color images were used for visual inspection of each window where macroalgae showed red or brown color in the enhanced 432 image. This approach can reduce the chance of misclassification, and is useful for extracting macroalgae pixels under optically complex water conditions. The areas of these macroalgae pixels were summed to give the total area $\left(\mathrm{A}_{\mathrm{T}}, \mathrm{Km}^{2}\right)$.

\subsection{Estimation of total biomass of floating macroalgae}

In order to estimate how much manpower would be needed to collect the floating macroalgae, managers need to estimate the potential total biomass of macroalgae $\left(\mathrm{B}_{\mathrm{M}}\right.$, ton). In this study, the total area completely covered by macroaglae $\left(\mathrm{A}_{\mathrm{CCM}}, \mathrm{Km}^{2}\right)$ and the unit biomass $\left(B_{U}\right.$, ton $\left./ \mathrm{Km}^{2}\right)$ were used to calculate the biomass using Eq. (1) below: $\mathrm{B}_{\mathrm{M}}=\mathrm{A}_{\mathrm{CCM}} * \mathrm{~B}_{\mathrm{U}}$,

where $\mathrm{B}_{\mathrm{U}}$ refers to the biomass per area (or pixels) for the study area completely covered by the aggregation of macroalgae.

$\mathrm{A}_{\mathrm{CCM}}$ was estimated from the macroalgae coverage, which was derived from the satellite image via the above-mentioned procedures. In high-resolution images, it is reasonable to assume that there should be sites where the sea surface was completely covered by macroalgae and the corresponding pixels should have the largest DVI values. The DVI values of all the macroalgae pixels were normalized, so the minimum and the maximum are 0 and 1, i.e., a term of [01DVI] where 0 is set to present that the pixel has $1 \%$ of macroalgae while 1 , for $100 \%$. Then, the portion of macroalgae (POM, \%) in each macroalgae pixel was calculated using Eq. (1), and $\mathrm{A}_{\mathrm{CCM}}$ was calculated using Eq. (2).

$\mathrm{POM}=99 *[01 \mathrm{DVI}]+1$,

$\mathrm{A}_{\mathrm{CCM}}=\sum_{\mathrm{i}=1}^{\mathrm{n}} \mathrm{POM}_{\mathrm{i}} * \mathrm{PS}_{\mathrm{i}}$,

where $\mathrm{n}$ is the number of pixels containing macroalgae; PS is the pixel size, e.g., $16 \mathrm{~m} * 16 \mathrm{~m}$ for GF-1 images. For more details, please go to Xing et al. (2017).

The unit biomass of macroalgae $\left(\mathrm{B}_{\mathrm{U}}\right.$, ton $\left./ \mathrm{Km}^{2}\right)$ was measured during the cruise conducted in the Jiangsu Shoal on 25 May 2016. In the field work, the floating macroalgae slicks or patches were visually 


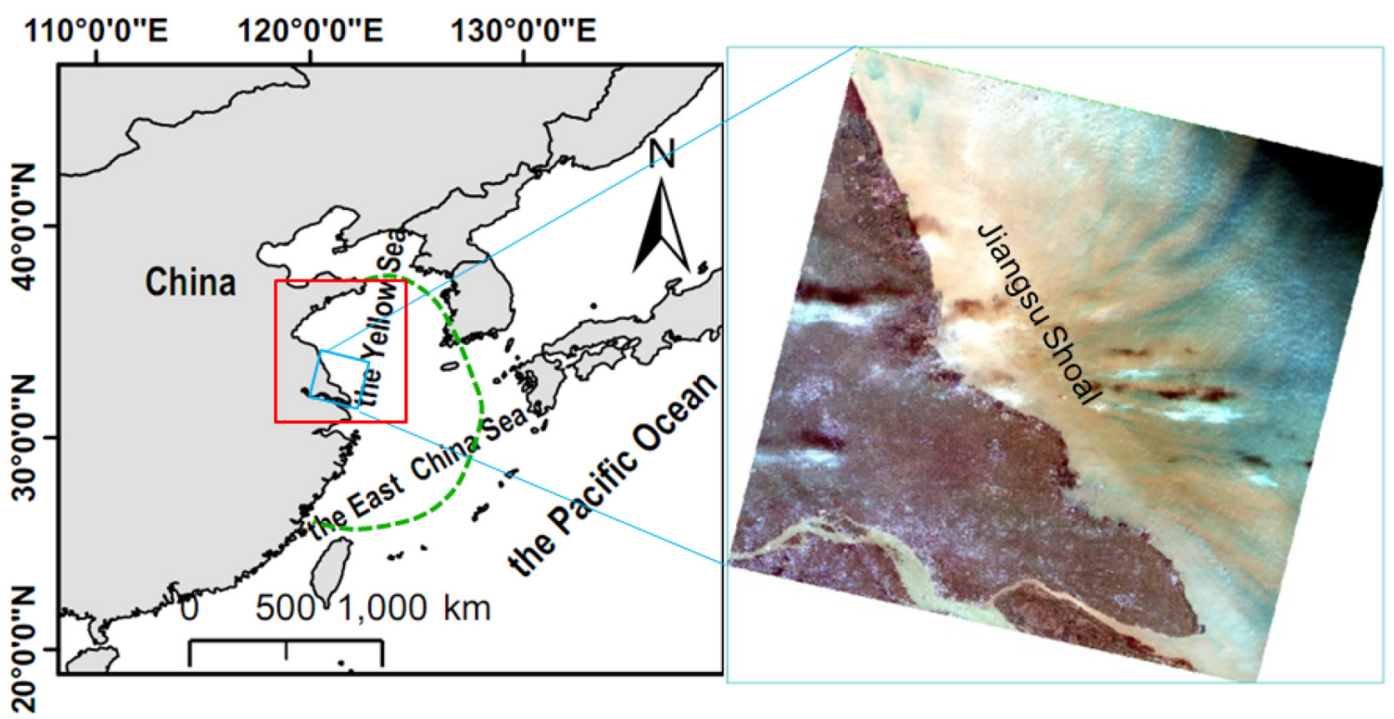

Fig. 1. The study area indicated by the red box. The true color image is a composite of GaoFen-1 bands 3 (red), 2 (green) and 1 (blue) acquired on 29 April 2016 . The dashed green line shows the region visited by large scale of macroalgal blooms in the Yellow Sea and the East China Sea. This figure is based on several studies (He et al., 2011; Xing et al., 2011, 2015b; Xing and Hu, 2016; Sun et al., 2017). (For interpretation of the references to color in this figure legend, the reader is referred to the web version of this article.)

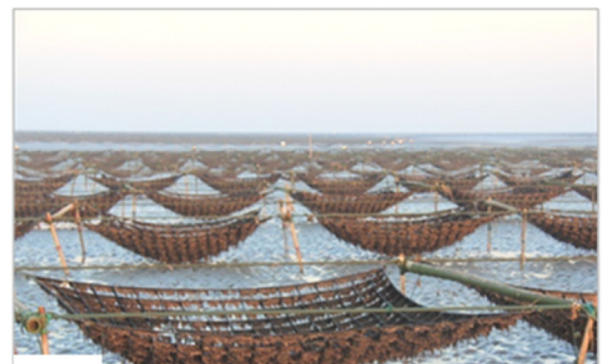

(a)

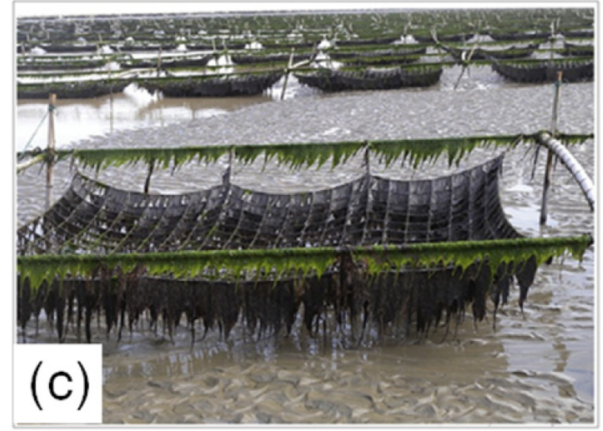

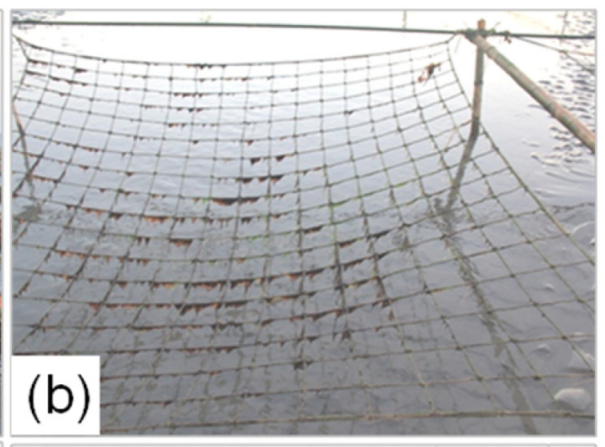

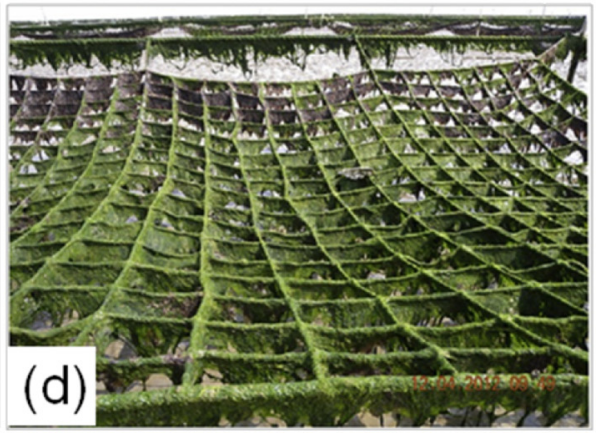

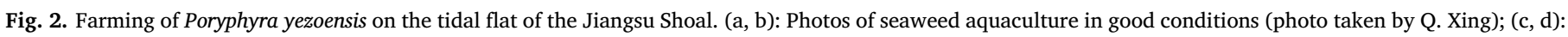
macroalgae growing on the farming facilities. After Zhou et al. (2015a).

inspected by the crew. When the sea surface was completely covered by macroalgae, a $0.1 \mathrm{~m}^{2}$ round-mouth fishing net was put under the macroaglae mats using a pole, and then the net was lifted out of water to collect the macroalgae while the surface of the net was being placed horizontally. Macroalgae attached to but outside of the net-mouth was cut and discarded, and the macroalgae in the net was immediately drained in the net and then wrapped in paper issue to remove the residual seawater. Finally, the wet weight $(\mathrm{Kg})$ of alive macroalgae was weighted, and the unit biomass of macroalgae $\left(\mathrm{Kg} / \mathrm{m}^{2}\right)$ was calculated. The measurements were repeated three times at each site, and the $\mathrm{B}_{U}$ values were $2.9,2.3$ and $2.6 \mathrm{Kg} / \mathrm{m}^{2}$, respectively, with an average of $2.6 \mathrm{Kg} / \mathrm{m}^{2}$, i.e., 0.26 ton $/ \mathrm{Km}^{2}$. In this work, $\mathrm{B}_{\mathrm{U}}$ was assumed to be a constant $\left(0.26 \mathrm{ton} / \mathrm{Km}^{2}\right)$ over the period from 29 April to 25 June 2016 when the macroalgae patches were in free-drifting state before accumulating in the coastal waters.

The workflow for image and data processing is outlined in Fig. 3. Once the biomass was calculated, the macroalgae collecting campaign can be evaluated.

\section{Results and discussion}

\subsection{Expansion of MABs in the Yellow Sea in 2016}

The initial sites and the drifting paths are the key factors for determining the areas for the collecting campaign. The red patches in Fig. 4 show the detailed spatio-temporal distribution of green tide 


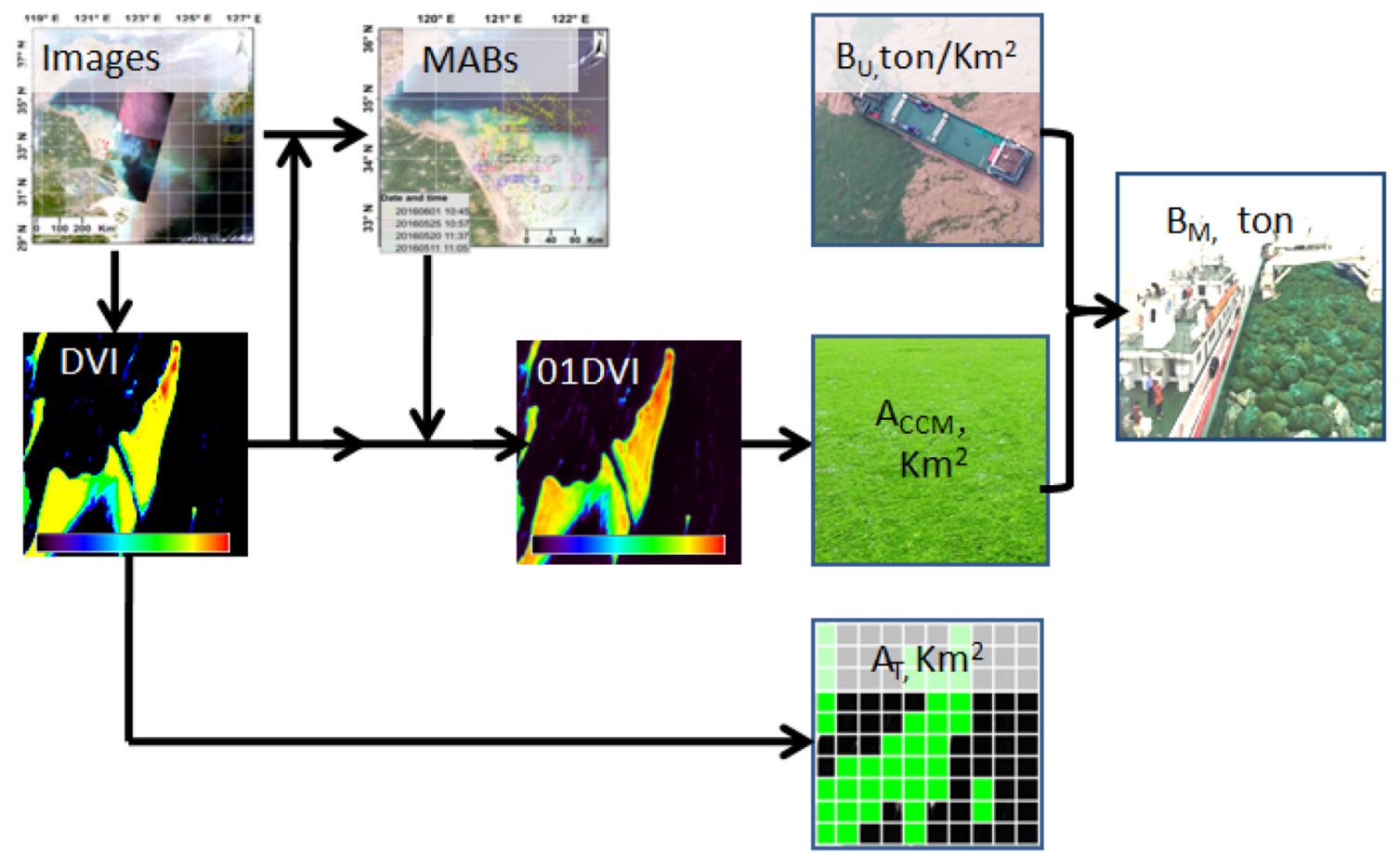

Fig. 3. The workflow chart for estimating total macroalgae biomass $\left(B_{M}\right)$ on the basis of satellite images and in-situ measured unit biomass ( $\left.B_{U}\right)$.

during the period from 29 April to 25 June 2016 in the Yellow Sea. The floating green macroalgae were first detected by GF-1 satellite in the Jiangsu Shoal on 29 April, and the impacted area expanded quickly in the northward direction. About one month later, on 1 June the floating macroalgae had moved from the turbid plumes of the Jiangsu Shoal into the relatively clear waters in the western Yellow Sea. These results show that the green tide initially occurred the aquaculture area in the Jiangsu Shoal. The time series of green tide from 29 April to 25 June show that it took about two months for floating macroalgae to drift northward from the Jiangsu Shoal to the Shandong Peninsula (for details, please see Supplement I for a GIF animation). Macroalgae blooms in early-May 2015 were also observed in the Jiangsu Shoal, and its northward drifting path was shown by high-resolution images (Zheng et al., 2016). The hypothesis on the source of green tide (Liu et al., 2009) is also supported by the observations here, i.e., floating macroalgae were produced while the facilities of Poryphyra yezoensis farming
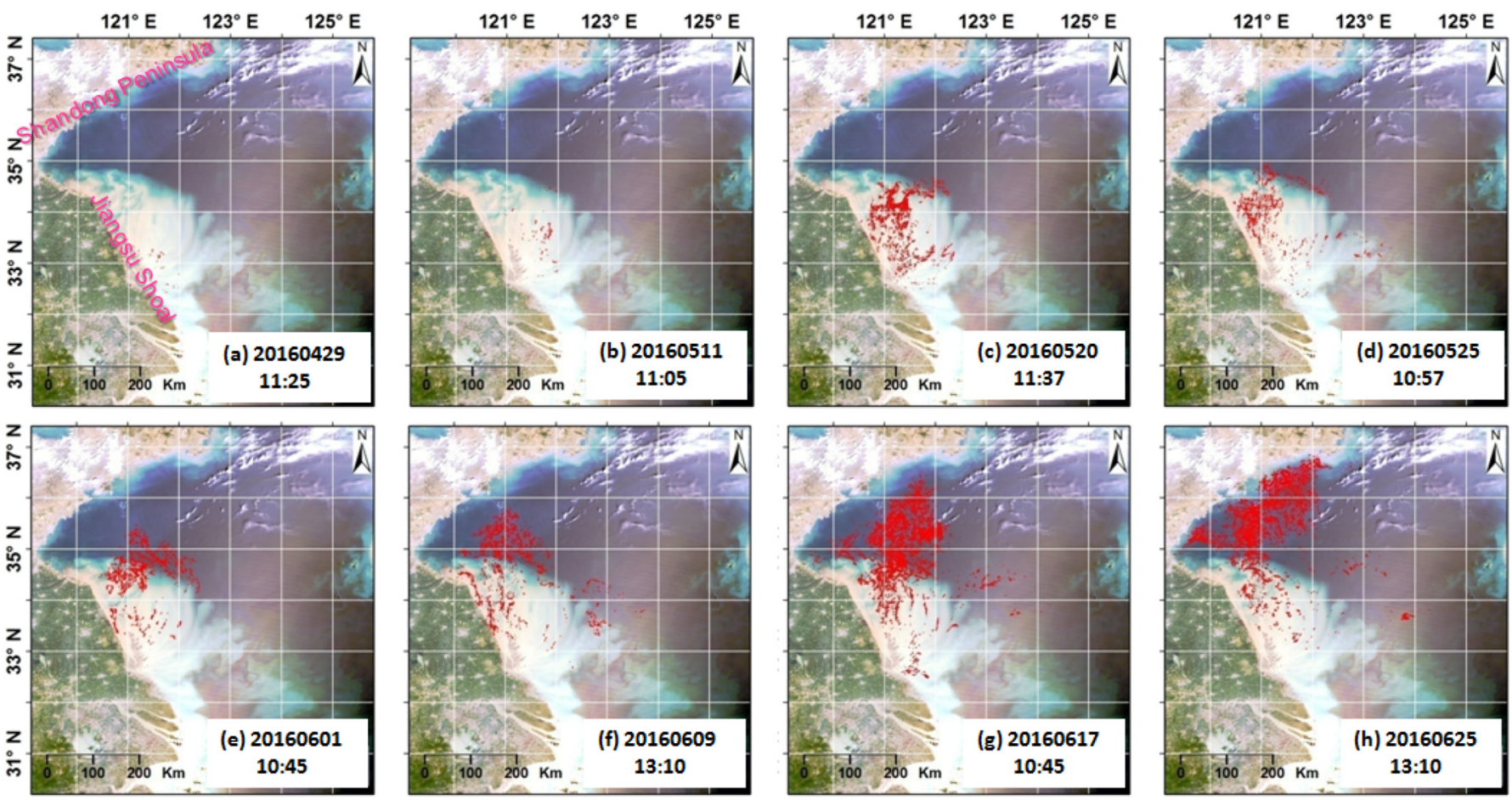

Fig. 4. Distributions of MABs (patches in red) from 29 April to 25 June 2016. The data were derived from satellite images whose acquisition date and time are shown in the format of YYYYMMDD HH:MM (local time). The background images are a true color composite by MODIS bands acquired on 30 April 2016 . (For interpretation of the references to color in this figure legend, the reader is referred to the web version of this article.) 
Table 1

Changes in macroalgae area and biomass in the Yellow Sea. ${ }^{a}$

\begin{tabular}{llllllll}
\hline $\begin{array}{l}\text { Date of 2016 } \\
\text { (Day of year) }\end{array}$ & $\begin{array}{l}\text { 11 May } \\
(131)\end{array}$ & $\begin{array}{l}\text { 20 May } \\
(140)\end{array}$ & $\begin{array}{l}\text { 25 May } \\
(145)\end{array}$ & $\begin{array}{l}\text { 1 June } \\
(152)\end{array}$ & $\begin{array}{l}\text { 9 June } \\
(160)\end{array}$ & $\begin{array}{l}\text { 17 June } \\
(168)\end{array}$ & $\begin{array}{l}\text { 25 June } \\
(176)\end{array}$ \\
\hline $\mathrm{A}_{\mathrm{T}}, \mathrm{Km}^{2}$ & 12 & 71 & 158 & 791 & 2098 & 3446 & 3319 \\
$\mathrm{~A}_{\mathrm{CCM}}, \mathrm{Km}^{2}$ & 2.5 & 13 & 35 & 153 & 320 & 442 & 539 \\
$\mathrm{~B}_{\mathrm{M}}, 10^{4}$ ton & 0.65 & 3.38 & 9.10 & 39.80 & 83.20 & 114.80 & 140.10 \\
$\mathrm{~A}_{\mathrm{CCM}} / \mathrm{A}_{\mathrm{T}}, \%$ & 21 & 18 & 22 & 19 & 15 & 13 & 16
\end{tabular}

a The unit biomass $\mathrm{B}_{\mathrm{U}}$ is set to 0.26 ton $/ \mathrm{Km}^{2}$ (see Section 2 on data and methods).

on the tidal flats of the Jiangsu Shoal were recycled.

\subsection{Changes in the coverage and biomass of MABs}

Table 1 shows the total area of macroalgae pixels $\left(\mathrm{A}_{\mathrm{T}}\right)$, the area completely covered by macroaglae $\left(\mathrm{A}_{\mathrm{CCM}}\right)$ and the corresponding biomass $\left(B_{M}\right)$ from 11 May to 25 June 2017. On 29 April, the scale of green tide first detected by GF-1 satellite might be too small to ensure that there were pure macroalgae pixels in the $16 \mathrm{~m} * 16 \mathrm{~m}$ image; thus, $\mathrm{A}_{\mathrm{CCM}}$ and $\mathrm{B}_{\mathrm{M}}$ were not calculated. On 25 June when the MABs reached the coastal waters of the Shandong Peninsula (Fig. 4), the total biomass of macroalgae was about $1,401,000$ tons, which is close to those observed in recent years (Hu et al., 2017).

In addition to the indices of $\mathrm{B}_{\mathrm{M}}$ and $\mathrm{A}_{\mathrm{CCM}}, \mathrm{A}_{\mathrm{T}}$ and other similar indices with which the sub-pixel portion of macroalgae is not taken into account were also used to evaluate the scale of MABs (Hu et al., 2010; Garcia et al., 2013; Xing et al., 2015a; Qi et al., 2016). In this work, we find that the ratio of $\mathrm{A}_{\mathrm{CCM}}$ to $\mathrm{A}_{\mathrm{T}}$ ranged from $13 \%$ to $22 \%$, with an average of $17.7 \%$; and the ratio was generally larger during the period from 11 May to 1 June ( $18 \%$ to $22 \%$ ) than that in the later period from 9 June to 25 June (13\% to $16 \%)$. As shown in Fig. 5, the latitude of $34.5^{\circ} \mathrm{N}$ can be roughly used as the boundary between the turbid plume of the Jiangsu Shoal and the relatively clear waters in the northward

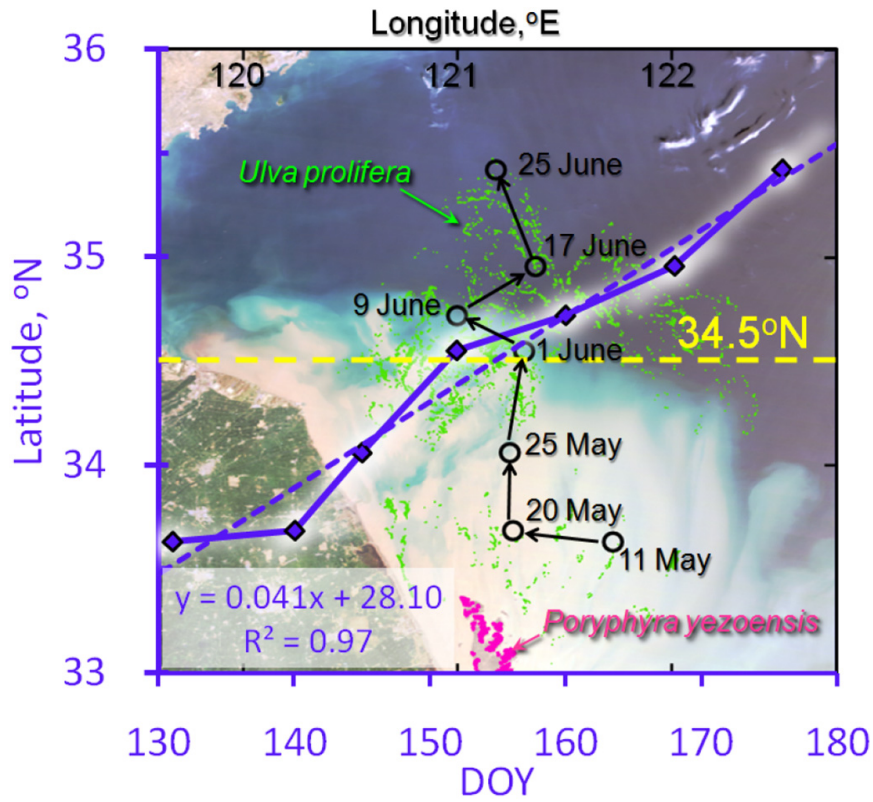

Fig. 5. The geometry centers (black circles) of green tides and the changes in the north latitude (blue solid line with diamonds). The yellow dashed line indicates $34.5^{\circ} \mathrm{N}$. The patches in green show the floating green macroalgae on 1 June 2016. The patches in magenta show the farming zones of Poryphyra yezoensis. The blue dashed line is a linearly-fitted line of the north latitude with the date (DOY, day of year), showing the due north drifting speed of about $0.041^{\circ}$ per day. (For interpretation of the references to color in this figure legend, the reader is referred to the web version of this article.)

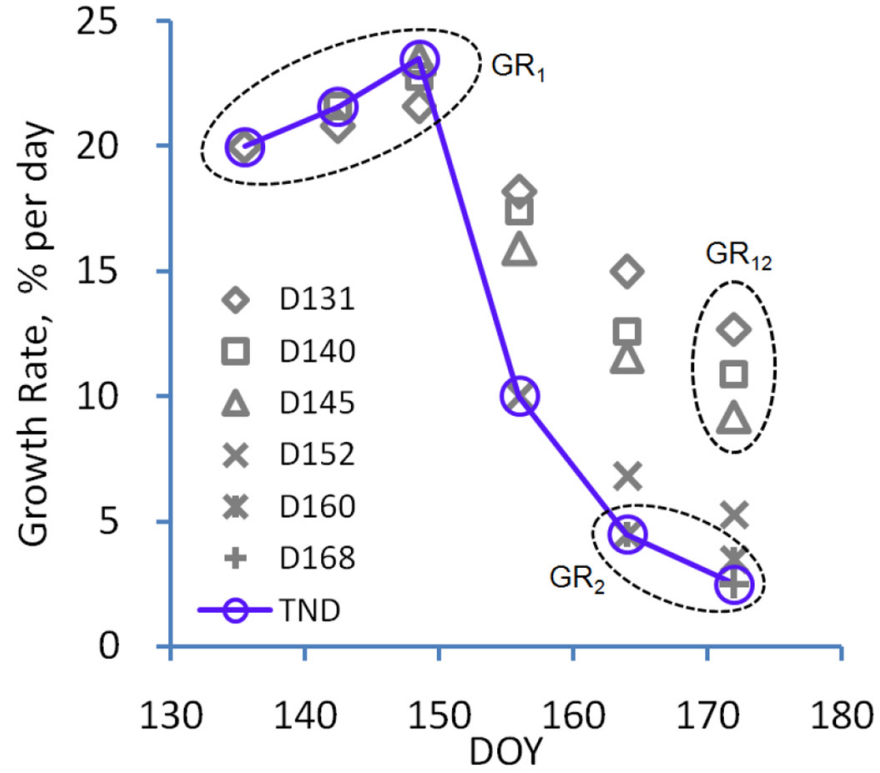

Fig. 6. Growth rates (\% per day) calculated for different drifting durations. The blue line with circles shows the growth rate in a period between every two neighboring dates (TND). Other points with the same symbols show the growth rates calculated against the periods from the same starting date to different ending dates (x-axis, DOY), e.g., $\diamond \mathrm{D} 131$ shows the growth rate with the starting date of 131 (DOY), i.e., 11 May 2016, and the ending date of 25 June 2016. The GR1 (20-25\%) presents the grow rate of MABs in the turbid plumes of the Jiangsu Shoal, while the GR2 $(2-5 \%)$, for the growth rate in the clear waters. The GR12 (9-13\%) covered the entire growing periods when the MABs drifted from the Jiangsu Shoal to the clear waters in the north. (For interpretation of the references to color in this figure legend, the reader is referred to the web version of this article.)

drifting path of MABs. As shown by the drifting path indicated by the sites of MABs' geometry centers, the MABs were mainly located in the turbid waters before 1 June, and they were in clear waters after 1 June (see Fig. 5). Qi et al. (2016) calculated the ratio of $\mathrm{A}_{\mathrm{CCM}}: \mathrm{A}_{\mathrm{T}}$ in a similar way for the maximum daily MABs, which were located north of $34.5^{\circ} \mathrm{N}$, and the derived ratios were 9-10\% in 2013, 2014 and 2015, which are close to our results (13\% to $16 \%)$ in the clear waters rather than those ( $18 \%$ to $22 \%$ ) observed over the turbid plumes of the Jiangsu Shoal.

\subsection{Growth rate of $M A B s$}

On the basis of the data of $\mathrm{B}_{\mathrm{M}}$ or $\mathrm{A}_{\mathrm{CCM}}$ shown in Table 1 , the growth rate (\% per day) was calculated for the periods from the same starting date to different ending dates. As shown in Fig. 6, the estimated growth rate varied with time and space. In general, the growth rate showed a sharp decrease from 20 to $25 \%$ to $3-5 \%$ when the MABs drifted northward from the turbid plume to the clear waters from 11 May to 25 June, i.e., crossing $34.5^{\circ} \mathrm{N}$.

The experiments using field cultures under controlled conditions (Zhang et al., 2013; Wang et al., 2015) showed that the growth rate of early blooms in the Jiangsu Shoal was $23-26 \%$, which is very close to the results $(20-25 \%)$ derived from satellite observations in this work. Hu et al. (2017) estimated the growth rate in the entire growing phase using the MODIS observations from 2008 to 2015, and found an average growth rate of $14.9 \%$ per day with which similar results (9-13\%) were obtained for the periods of 11 May-25 June, 20 May-25 June and 25 May-25 June.

The nutrient supply also supported this spatial pattern of the growth rate of MABs, i.e., higher growth rate in the southern turbid plume of the Yellow Sea than in the northern clear waters. Higher nutrient supply in the Jiangsu Shoal (Xing et al., 2010, 2015a; Keesing et al., 2011; Zhou et al., 2015b) as well as more favorable water temperature 


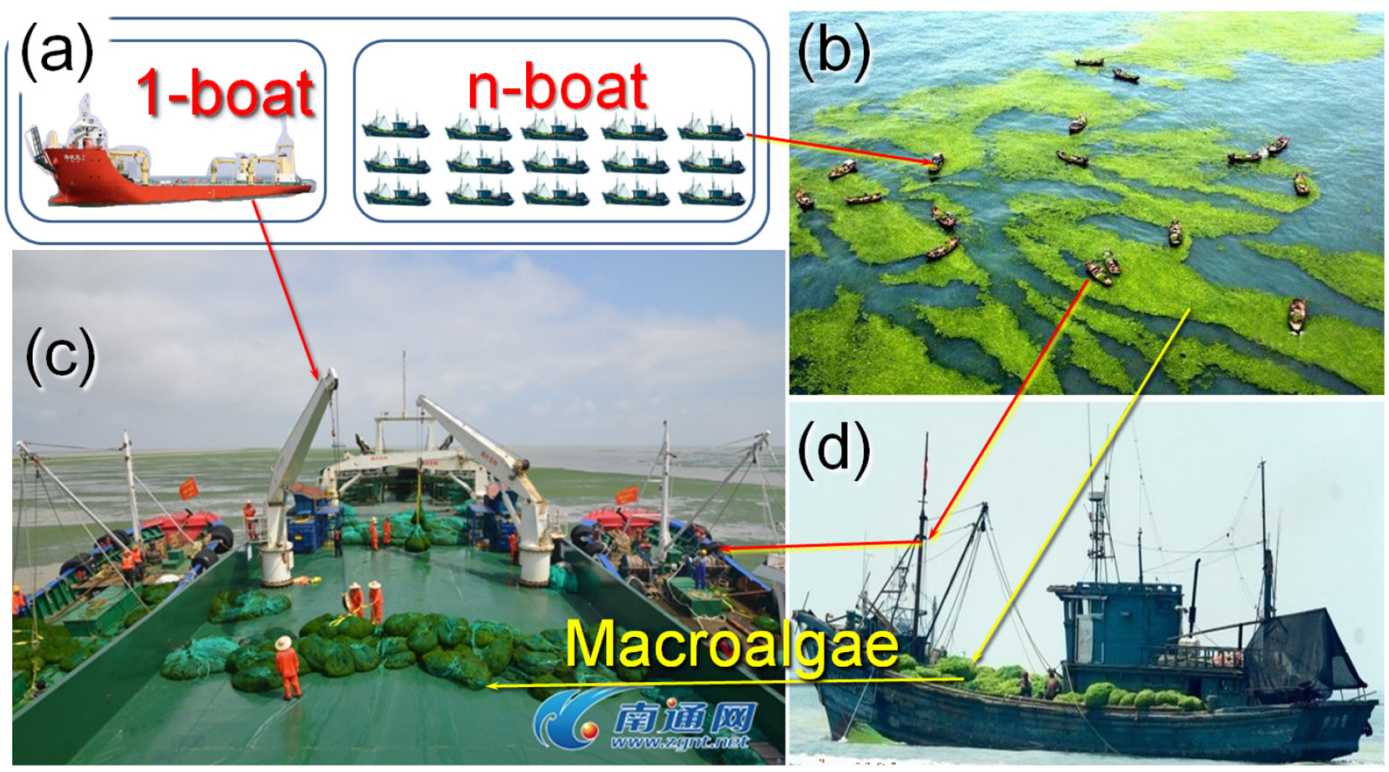

Fig. 7. (a) The schema of a " $1+n$ " fleet model for macroalgae collecting, (b) n-boats in collecting macroalgae, (c) 1-boat in receiving macroalgae parcels, and (d) a small boat sending the collected-macroalgae to 1-boat (JSChina, 2016; photos credits: Qingdao news, Nantong news).

(Liu et al., 2009; Xing et al., 2015a) would support a faster growth of green macroalgae in this region. The turbid waters in the Jiangsu Shoal (Wang et al., 2011) would reduce the light availability under the surface water, which however had negligible effect on the floating macroalgae at the water surface.

\section{Implications on early-stage macroalgae collecting campaign}

Massive macroalgae collecting campaigns have been carried out to mitigate the impacts every summer in the Yellow Sea since 2008. Such campaigns cost huge amount of money; e.g., one billion Chinese Yuan was spent on combating the green tide in 2008 (Wang et al., 2011). During the past years, many equipments and collecting strategies were used to improve the effectiveness of macroalgae collecting campaigns (Wang, 2015; JSChina, 2016).

In the late spring and summer 2016, macroalgae collecting campaigns were carried out in the Yellow Sea. In these field campaigns, a " $1+\mathrm{n}$ " fleet model, a useful model in practice for macroalgae-harvesting (see Supplement I for an example), was used to collect macroalgae. As shown by Fig. 7 , the " $1+\mathrm{n}$ " fleet is composed of a big boat and a number of small boats: " 1 " represents one specially-designed boat (3000-5000 displacement tons) with the capability of receiving macroalgae, de-watering, storing, transportation, and so on; and " $\mathrm{n}$ " represents a number of fishing boat (each with $\sim 100$ displacement tons) equipped with specially-designed nets to collect macroalgae; the number " $n$ " usually ranges from 10 to 50 . The results of collecting campaigns showed that a fishing boat usually collected about 25 tons of macroalgae per day, and a " $1+\mathrm{n}$ " fleet might collect 1000-2000 tons of macroalgae, depending on the scale of the fleet (JSChina, 2016).

The standing biomass $\left(\mathrm{B}_{\mathrm{T}}\right)$ and the growth rate $(\mathrm{GR})$ are the essential factors for predicting the biomass, and for further calculating the response effort, which should be invested to control the green tide. For the only purpose of clearing all of the floating macroalgae, in theory, the earlier the collecting activities start, the less the biomass there is for collecting, and thus less effort would be needed. For example, if a collecting campaign was conducted on 11 May with a standing biomass of 6500 tons (Table 1), no more than 8125 tons (a growth rate of $25 \%$ is assumed) need to be collected. And under ideal conditions, all the macroalgae could be removed in one day. However, in practice it is difficult to detect all the sparsely-distributed small patches of macroalgae in the early stage of green tide. Moreover, it is difficult to access the shallow waters in the tidal zone.

Under the forcing of surface wind and currents, the macroalgae patches tend to aggregate in specific zones where the floating macroalgae are suitable for more efficient in-situ collecting, e.g., in the convergence zone (Hu et al., 2014; Xing and Hu, 2016), the tidal channel, and so on. So, a more practical plan may be first considered to control the green tide under a manageable scale at the initial stage. For example, for the purpose of no more increase in biomass since 11 May, the critical collecting capability should be 1625 ton ( 6500 ton $* 25 \%$ ) per day. In the same way, if it starts from 20 May, the collecting capability should be 8450 ton per day. However, if it starts from 25 May, the collecting capability should be 22,750 ton per day, and accordingly it needs more than 10-30 fleets to achieve this goal, which is difficult to succeed.

The above analysis suggests that the early-stage green tide might be manageable in an economic way at the initial sites, i.e., at the Jiangsu Shoal; and due to the rapid increase in biomass at the Jiangsu Shoal, the time window is also limited. For the 2016 case, the time window was no more than 14 days.

In this study, $B_{U}=2.6 \mathrm{~kg} / \mathrm{m}^{2}$ is used to calculate the absolute total biomass of macroalgae. The value of $\mathrm{B}_{\mathrm{U}}$ may vary with actual conditions. For instance, for the green tide in the Qingdao coastal waters, $\mathrm{B}_{U}$ had higher values of $3.5-4.4 \mathrm{~kg} / \mathrm{m}^{2}$ (Hu et al., 2017) due to stronger accumulation effect jointly caused by tides, wind, currents, and especially the blocking of macroalgae's drifting path. Accordingly, using Eq. (1), $B_{U}$ can be replaced by the new value to estimate total biomass and further assess the capability for macroalgae collecting in the Qingdao coastal waters.

\section{Concluding remarks and prospective}

To control green tide at the early stage through macroalgae collecting, high-resolution satellite remote sensing images were used to reveal the expanding process of early-stage green tide from the Jiangsu Shoal, and to estimate the corresponding growth rate. Combining the analysis on the macroalgae collecting capability with the biomass change, we showed in this study that the early-stage green tide is manageable by macroalgae collecting effort although the time window might be no more than two weeks.

In addition to the green tide shown in this work, "golden tide" caused by floating Sargassum also occurred in Chinese coastal seas, 
which might lead to ecologic damages. We suggest that a regional satellite monitoring system be established over the Yellow Sea and the East China Sea to help manage the floating macroalgae blooms. The green macroalgae collecting plan could be modified to control the golden tide for the purpose of managing bio-resources and/or hazardous materials. Especially, high-resolution satellite images should be included to detect early blooms and estimate their biomass.

With the consideration of marine transportation cost, the land/ harbor processing capability and the macroalgae product, economic plan can be determined to carry out these types of collecting campaigns. The biomass distribution maps and drifting paths derived from satellite images can be used to set the priority zones or transects for macroalgae collecting and for allocating the collecting resources and facilities more efficiently.

\section{Acknowledgements}

This work was jointly supported by the National Natural Science Foundation of China (41676171, 41476159), the Qingdao National Laboratory for Marine Science and Technology of China (2016ASKJ02) and the China Agriculture Research System (CARS-50). We acknowledge the China-Korea Joint Ocean Research Center for its support of the research through Project PI-2017-3. The authors are grateful for the helpful comments from the anonymous reviewers and the encouragement from Prof. Sam Purkis from the University of Miami.

\section{Appendix A. Supplementary data}

Supplementary data to this article can be found online at https:// doi.org/10.1016/j.marpolbul.2018.05.035.

\section{References}

Cui, T., Zhang, J., Sun, L., Jia, Y., Zhao, W., Wang, Z., Meng, J., 2012. Satellite monitoring of massive green macroalgae bloom (GMB): imaging ability comparison of multisource data and drifting velocity estimation. Int. J. Remote Sens. 33, 5513-5527.

Ding, Y., Huang, J., Cui, T., et al., 2015. The decomposition method of MODIS images Enteromorpha mixed pixels based on the relation of NDVI to abundance. Acta Oceanol. Sin. 37 (7), 123-131 (In Chinese with English Abstract).

Garcia, R.A., Fearns, P., Keesing, J.K., Liu, D., 2013. Quantification of floating macroalgae blooms using the scaled algae index. J. Geophys. Res. Oceans 26-42.

Gower, J., Young, E., King, 2013. S. Satellite images suggest a new Sargassum source region in 2011. Remote Sens. Lett. 4, 764-773.

Hu, C., 2009. A novel ocean color index to detect floating algae in the global oceans. Remote Sens. Environ. 113, 2118-2129.

Hu, C., He, M.X., 2008. Origin and offshore extent of floating algae in Olympic sailing area. Eos. Trans. AGU 89, 302-303.

Hu, C., Li, D., Chen, C., Ge, J., Muller-Karger, F.E., Liu, J., ... He, M.-X., 2010. On the recurrent Ulva prolifera blooms in the Yellow Sea and East China Sea. J. Geophys. Res. 115, C05017. http://dx.doi.org/10.1029/2009JC005561.

Hu, S., Yang, H., Zhang, J., Chen, C., He, P., 2014. Small-scale early aggregation of green tide macroalgae observed on the Subei Bank, Yellow Sea. Mar. Pollut. Bull. 81, 166-173.

Hu, L., Hu, C., He, M., 2017. Remote estimation of biomass of Ulva prolifera macroalgae in the Yellow Sea. Remote Sens. Environ. 192, 217-227.

JSChina, 2016. http://news.southcn.com/community/content/2016-06/17/content 149657090.htm, Accessed date: 12 November 2017.

Keesing, J.K., Liu, D., Fearns, P., Garcia, R., 2011. Inter- and intra-annual patterns of Ulva prolifera green tides in the Yellow Sea during 2007-2009, their origin and relationship to the expansion of coastal seaweed aquaculture in China. Mar. Pollut. Bull. 62, 1169-1182.

Li, L., Xing, Q., Yu, D., Zhang, J., 2018. Assessment of the impacts from the world's largest floating macroalgae blooms on the water clarity at the west Yellow Sea using MODIS data (2002-2016). IEEE J. Sel. Top. Appl. Earth Obs. Remote Sens. http://dx.doi.org/ 10.1109/JSTARS. (2018.2806626).

Liu, D., Keesing, J.K., Xing, Q., Shi, P., 2009. World's largest macroalgal bloom caused by expansion of seaweed aquaculture in China. Mar. Pollut. Bull. 58, 888-895.

Liu, D., Keesing, J.K., He, P., Wang, Z., Shi, Y., Wang, Y., 2013a. The world's largest macroalgal bloom in the Yellow Sea, China: formation and implications. Estuar. Coast. Shelf Sci. 129, 2-10.

Liu, F., Pang, S., Chopin, T., Gao, S., Shan, T., Zhao, X., Li, J., 2013b. Understanding the recurrent large-scale green tide in the Yellow Sea: temporal and spatial correlations between multiple geographical, aquacultural and biological factors. Mar. Environ. Res. 83, 38-47.

Liu, X., Wang, Z., Zhang, X., 2016. A review of the green tides in the Yellow Sea, China.
Mar. Environ. Res. 119, 189-196.

Liu, X., Wang, Z., Fan, S., et al., 2017. The distribution of green algal micro-propagules and macroalgae at the early stage of green tide in the coastal area of South Jiangsu Province in 2014. J. Ocean Univ. China 16, 81. http://dx.doi.org/10.1007/s11802017-3008-2. (in Chinese with English abstract).

Lotze, Heike, Schramm, Winfrid, Schories, Dirk, Worm, Boris, 1999. Control of macroalgal blooms at early developmental stages: Pilayella littoralis versus Enteromorpha spp. Oecologia 119, 46-54. http://dx.doi.org/10.1007/s004420050759.

Meng, R., Xing, Q., 2013. Detection of offshore ship and well platformbased on optical remote sensing images. J. Comput. Appl. 33, 708-711.

Qi, L., Hu, C., Xing, Q., Shang, S., 2016. Long-term trend of Ulva prolifera blooms in the western Yellow Sea. Harmful Algae 58, 35-44.

Shi, W., Wang, M., 2009. Green macroalgae blooms in the Yellow Sea during the spring and summer of 2008. J. Geophys. Res. Oceans 114, C12010. http://dx.doi.org/10. 1029/2009JC005513.

Smetacek, V., Zingone, A., 2013. Green and golden seaweed tides on the rise. Nature 504, 84-88.

Son, Y.B., Min, J.E., Ryu, J.H., 2012. Detecting massive green algae (Ulva prolifera) blooms in the Yellow Sea and East China Sea using Geostationary Ocean Color Imager (GOCI). Ocean Sci. J. 47 (3), 359-375.

Son, Y.B., Choi, B.-J., Kim, Y.H., Park, Y.-G., 2015. Tracing floating green algae blooms in the Yellow Sea and the East China Sea using GOCI satellite data and Lagrangian transport simulations. Remote Sens. Environ. 156, 21-33.

Sun, X., Wu, M., He, F., et al., 2017. Temporal and spatial distribution of Ulva prolifera in the Yellow Sea and influence of typhoon "CHANGHOM" in 2015. Remote Sens. Technol. Appl. 32 (5), 921-930 (in Chinese).

Wang, X., 2015. On the marine collecting techniques of floating macroalgae. In: Hebei Fisheries, http://dx.doi.org/10.3969/j.issn.1004-6755.2015.03.018. (In Chinese).

Wang, M., Hu, C., 2016. Mapping and quantifying Sargassum distribution and coverage in the central West Atlantic using MODIS observations. Remote Sens. Environ. 183, $356-367$.

Wang, X.H., Li, L., Bao, X., Zhao, L.D., 2009. Economic cost of an algae bloom cleanup in China's 2008 Olympic Sailing Venue. EOS Trans. Am. Geophys. Union 90, 238-239.

Wang, X.H., Qiao, F.L., Lu, J., Gong, F., 2011. The turbidity maxima of the northern Jiangsu shoal-water in the Yellow Sea, China. Estuar. Coast. Shelf Sci. 93, 202-211.

Wang, Z., Xiao, J., Fan, S., Li, Y., Liu, X., Liu, D., 2015. Who made the world's largest green tide in China?-an integrated study on the initiation and early development of the green tide in Yellow Sea. Limnol. Oceanogr. 60, 1105-1117. http://dx.doi.org/ 10.1002/lno.10083.

Xiao, Y., Zhang, J., Cui, T., 2017. High-precision extraction of nearshore green tides using satellite remote sensing data of the Yellow Sea, China. Int. J. Remote Sens. 38 (6), 1626-1641.

Xing, Q., Hu, C., 2016. Mapping macroalgal blooms in the Yellow Sea and East China Sea using HJ-1 and Landsat data: application of a virtual baseline reflectance height technique. Remote Sens. Environ. 178, 113-126.

Xing, Q., Loisel, H., Schmitt, F., Shi, P., Liu, D., Keesing, J., 2009. Detection of the green tide at the Yellow Sea and tracking its wind-forced drifting by remote sensing. Geophys. Res. Abstr. 11 EGU General Assembly 2009, Vienna (EGU2009-577).

Xing, Q., Liu, D., Liang, S., Yu, D., Shi, P., 2010. Remote sensing of the transportation of green tide from the aquaculture area of the northern Jiangsu coast to Qingdao of Shandong. In: Environmental Impact Assessment in China. 12. pp. 10-14 (In Chinese).

Xing, Q., Zheng, X., Shi, P., Hao, J., Yu, D., Liang, S., ... Zhang, Y., 2011. Monitoring "GreenTide" in the Yellow Sea and the East China Sea using multi-temporal and multi-source remote sensing images. Spectrosc. Spectr. Anal. 31, 1644-1647 (in Chinese with English abstract).

Xing, Q., Hu, C., Tang, D., Tian, L., Tang, S., Wang, X.H., Lou, M., Gao, X., 2015a. World's largest macroalgal blooms altered phytoplankton biomass in summer in the Yellow Sea: satellite observations. Remote Sens. 7, 12297-12313.

Xing, Q., Tosi, L., Braga, F., Gao, X., Gao, M., 2015b. Interpreting the progressive eutrophication behind the world's largest macroalgal blooms with water quality and ocean color data. Nat. Hazards 78, 7-21.

Xing, Q., Guo, R., Wu, L., ... Li, X., 2017. High-resolution satellite observations of a new hazard of golden tides caused by floating Sargassum in winter in the Yellow Sea. IEEE Geosci. Remote Sens. Lett. 14 (10), 1815-1819.

Xu, Q., Zhang, H., Cheng, Y., Zhang, S., Zhang, W., 2016a. Monitoring and tracking the green tide in the Yellow Sea with satellite imagery and trajectory model. IEEE J. Sel. Top. Appl. Earth Obs. Remote Sens. http://dx.doi.org/10.1109/JSTARS.2016. 2580000.

Xu, F., Gao, Z., Ning, J., Zheng, X., Liu, C., Gao, W., 2016b. Error analysis on Green Tide monitoring using MODIS data in the Yellow Sea based on GF-1 WFV data. In: Proc. SPIE 9975 Remote Sensing and Modeling of Ecosystems for Sustainability XIII, , 99750P (19 September 2016). https://doi.org/10.1117/12.2235908.

Zhang, J., Huo, Y., Yu, K., Chen, Q., He, Q., Han, W., Chen, L., Cao, J., Shi, D., He, P., 2013. Growth characteristics and reproductive capability of green tide algae in Rudong coast, China. J. Appl. Phycol. 25, 795-803.

Zheng, X., Gao, Z., Ning, J., Xu, F., Liu, C., Sun, Z., 2016. Remote sensing monitoring of green tide in the Yellow Sea in 2015 based on GF-1 WFV data. In: Proc. SPIE 9975, Remote Sensing and Modeling of Ecosystems for Sustainability XIII, , 99750L (19 September 2016). https://doi.org/10.1117/12.2235833.

Zhou, M.-J., Liu, D., Anderson, D.M., Valiela, I., 2015a. Introduction to the special issue on green tides in the Yellow Sea. Estuar. Coast. Shelf Sci. 163. http://dx.doi.org/10 1016/j.ecss.2015.06.023.

Zhou, Y.P., Tan, L.J., Pang, Q.T., Li, F., Wang, J.T., 2015b. Influence of nutrients pollution on the growth and organic matter output of Ulva prolifera in the southern Yellow Sea, China. Mar. Pollut. Bull. 95 (1), 107-114. 